\title{
MODIFIED HEXANIT CUTTERS FOR KNURLING OF CYLINDRICAL SHAFT SECTIONS
}

\author{
Bogdan Korobko ${ }^{1}$, Ievgen Vasyliev ${ }^{2}$, Stanislav Popov ${ }^{3}$, Anatoly Vasilyev ${ }^{4}$ \\ ${ }^{1}$ Department of Construction Machinery and Equipment, National University «Yuri Kondratyuk Poltava Polytechnic», Poltava, Ukraine \\ ORCID: http://orcid.org/0000-0002-9086-3904 \\ ${ }^{2}$ Department of Construction Machinery and Equipment, National University «Yuri Kondratyuk Poltava Polytechnic», Poltava, Ukraine \\ ORCID: http://orcid.org/0000-0001-5133-3989 \\ ${ }^{3}$ Department of Construction Machinery and Equipment, National University «Yuri Kondratyuk Poltava Polytechnic», Poltava, Ukraine \\ kaf054@i.ua \\ ORCID: http://orcid.org/0000-0003-2381-152X \\ ${ }^{4}$ Department of Construction Machinery and Equipment, National University «Yuri Kondratyuk Poltava Polytechnic», Poltava, Ukraine \\ ORCID: http://orcid.org/0000-0002-1767-8569
}

ARTICLE INFO

Article history:

Received date 18.12.2019

Accepted date 09.01.2020

Published date 31.01.2020

Section:

Machine building and metal processing

D O I

$10.21303 / 2313-8416.2020 .001147$

KEYWORDS

diamond smoothing

knurling, knurler

turning tool

Hexanit R

superhard materials

\section{A B S TRACT}

The possibility of using conventional cutters, in which the super-hard materials Hexanit $\mathrm{R}$ acts as the material for the diamond knurling of shaft sections made of steel 10 , has been investigated. It is recommended to use damaged replaceable tips with super-hard material as tool blanks, which requires either re-grinding or recycling. The possibility of restoring the working properties of such cutters by regrinding is established, provided that the core of the tool is precisely located relative to the axis of rotation of the workpiece. The design of tooling in the form of a mandrel for fixing the tool on a lathe is proposed. It allows flexible clamping of the tool to the workpiece. Design and operational processing parameters are recommended for diamond knurling using tips made of superhard Hexanit-R material: knurler radius $-5 \mathrm{~mm}$; clamping forces $200 \mathrm{~N}$; feed $-0.05 \mathrm{~mm} / \mathrm{rev}$; workpiece rotation frequency $-630 \mathrm{rpm}$. According to the knurling results, the roughness was Ra $0.8 \mu \mathrm{m}$ when lubricated with I-20A mineral industrial oil. An increase in the number of passes greater than four did not lead to a significant improvement in surface roughness. No signs of wear, damage to the working surface of the tool after an operating time of 40 hours were found.

(C) The Author(s) 2020. This is an open access article under the CC BY license http://creativecommons.org/licenses/by/4.0).

\section{Introduction}

In the conditions of repair shops, in most cases there is a limited list of metal-cutting equipment. Most often these are turning and drilling machines [1]. The limited funding for such workshops also determines the lack of a specialized tool [2]. But when performing restoration and repair work, it often becomes a matter of finishing operations for the surfaces of the shaft sections. The process of using modern methods of diamond smoothing is attractive. It allows, in the presence of only a lathe, to perform finishing operations for cylindrical sections of shafts. The process has significant advantages, namely: improving the surface roughness without the use of abrasive materials (sandpaper), strengthening surface hardness [3, 4]. In addition, in some repair situations, there is a need for a slight reduction in the diametrical size of the shaft seating surface, especially after repeated reinstallation on the machine. Repeated turning for a slight reduction in diametric dimensions by conventional methods, especially after reinstallation, is extremely problematic [5].

The process of diamond smoothing requires the presence of the tips themselves with diamonds, and mandrels for fixing them on a lathe. Most diamond tips for diamond smoothing are made of both natural and synthetic diamonds, but their cost is not always economically affordable.

Turning of heat-treated steels, cast iron, deposited hard surfaces and other surfaces with a hardness of HRC 60-64 is possible only with the use of cutters that use superhard materials (SHM) as the material of the cutting part. In most cases, SHMs such as borazon or Hexanit are used as SHMs. Hexanit is more widespread, which allows turning in comparison with borazon, and tips for turning cutters made of this material are always present in every turning workshop. Fig. 1 shows the appearance of turning tools with the material of the cutting part made of SHM. 
A feature of cutters made of SHMs is that despite their high hardness HV, which is 50$60 \mathrm{GPa}$, they withstand up to 5-6 regrindings on a regular diamond wheel during operation. Therefore, it is of interest to reuse SHM cutters, which are no longer suitable for turning, but still retain the SHM core in them. The appearance of damaged replaceable tips made of SHMs is shown in Fig. 2. The core in the form of a cylinder with a diameter of 6 and a height of $5 \mathrm{~mm}$ is used as SHM. As if the indicated cylinder size is enough to form the cutting angle, the replaceable tip is regrind for subsequent use (Fig. 2, a). But there is always the possibility of regrinding the tip made of SHM to use it for diamond knurling (Fig. 2, b).

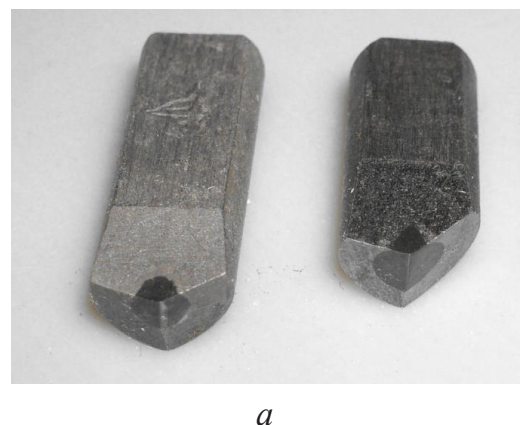

$a$

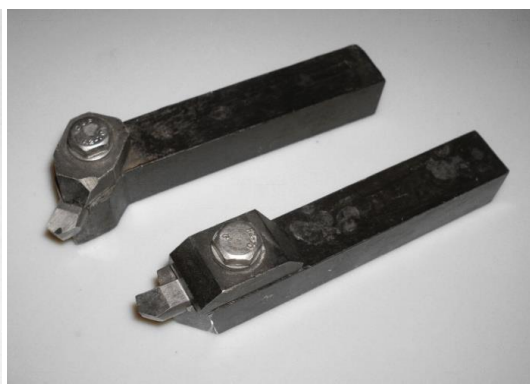

$b$

Fig. 1. Turning cutters with cutting material made of superhard materials: $a$ - interchangeable tips; $b$ - cutter assembly

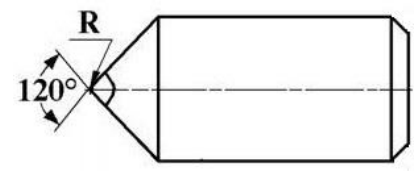

$a$

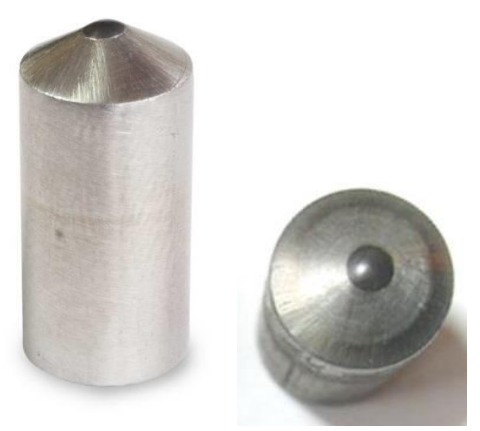

$b$

Fig. 2. Diamond tip for smoothing: $a$-outline sketch; $b$-side and top appearance of the smoother

\section{Literature review}

The process of diamond smoothing is quite widespread in machine-building production $[6,7]$. It is economically feasible through existing domestic production of diamond tips. The view of the diamond tip for smoothing is shown in Fig. 3. It consists of a mandrel and a working core.

As a working core, the following materials of two groups are presented [8]. The first group is represented by single-crystal from both natural and synthetic diamonds. They are characterized by excessively high microhardness, good thermal conductivity, but limited thermal stability. More widely compared with natural ones, common monocrystalline synthetic diamonds (SD), for example, AST brand. They are not much inferior in microhardness, having similar parameters both in heat resistance $-600-700{ }^{\circ} \mathrm{C}$, and in thermal conductivity.

The second group is represented by diamond-based synthetic polycrystalline materials (SPD), for example, ASPK brand. ASPK polycrystals have a fine-grained structure in the form of firmly cemented masses. Heat resistance has the best value and is in the range of $900-1000{ }^{\circ} \mathrm{C}$.

The influence of the components of the processing on the quality of the treated surface is considered in $[9,10]$. In particular, not only steel alloys are considered, but also alloys based on aluminum [11]. The price range of domestically produced diamond tips can be tracked on the Prom. ua trading platform. It most widely represented of smoothers with the brand of the working core ASPK-3, the cost of which is $16-25$ c. u. [12]. 
The ST series tool is presented as the most modern equipment for smoothing [13]. It is equipped with both a holder and a smoothing tip. The tip is made of natural diamond. The cost is 224-304 c. u. depending on the technological purpose.

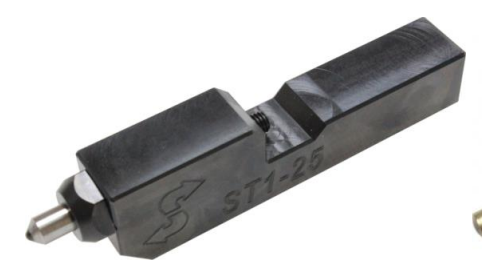

$a$

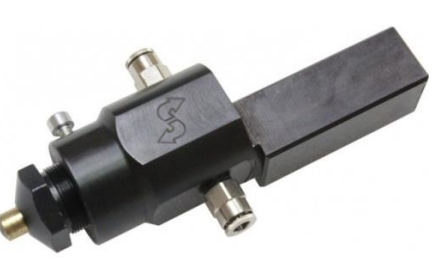

$b$

Fig. 3. Equipment of various designs for diamond smoothing of the ST series: $a$ - fixed preload is provided; $b$ - cooling is provided, in addition

Diamond refers to superhard materials created by nature. For the materials considered, used as a core in the tips for smoothers, the microhardness value is given in Table $\mathbf{1}$.

Table 1

Microhardness of natural and polycrystalline diamonds that are used in diamond smoothers

\begin{tabular}{ccc}
\hline \multicolumn{2}{c}{ Material } & Microhardness, GPa \\
\hline Natural or artificial diamond single crystal & 100 \\
Polycrystalline diamonds & ACПК & $80-100$ \\
& AКTM & $50-60$
\end{tabular}

It is of interest to consider the possibility of using "Hexanit-R" SHM [14] as the material for the core in the tips for diamond smoothing, as such, which is always present at the turner's workplace. It is able to work under conditions of shock loads when turning hardened steels and other grades of materials; providing an increase in productivity by 4-10 times in comparison with carbides in operations of semi-finishing and finishing turning.

In addition, the processing of steels or cast irons using tools made of natural or artificial diamonds is not recommended, since carbon, which is a component of these materials, can react with diamond. Hexanit does not fall under this requirement, but rather, is recommended for this treatment as such, made on the basis of boron nitride.

\section{The aim and objectives of research}

The aim of research is to test the possibility of using conventional cutters with a cutting edge material made of "Hexanit-R" SHM for diamond knurling.

To achieve the aim, the following objectives are set:

- explore the possibility of using "Hexanit-R" SHM for the operation of diamond knurling sections of the shafts made of St10;

- determine the possibility of regrinding the used tips made of "Hexanit-R" SHM from turning tools for use as diamond guides with the possible shape of their working surface being protected;

- establish the recommended processing modes for the diamond knurling operation for tips made of "Hexanit-R" SHM.

\section{Materials and methods of research}

The process of diamond smoothing is carried out by diamond tips, in which the material for the working core is used SHM based on polycrystalline diamonds (PCD), the microhardness of which is in the range of 50-100 GPa. Recently, a large number of superhard materials have been synthesized. In addition to those considered, cubic boron-borazon nitride and hexagonal boron-hexanit nitride are most widely used in turning. Let's consider the mechanical characteristics of conditioned polycrystalline diamonds, the data of which are given in Table 2. 
Table 2

Mechanical properties of superhard materials (SHM) based on polycrystalline diamonds (PCD)

\begin{tabular}{cccccc}
\hline \multirow{2}{*}{ Material } & $\begin{array}{c}\text { Microhardness, } \\
\text { GPa }\end{array}$ & \multicolumn{2}{c}{ Strength, GPa } & Thermal conductivity, W/(m K) & Heat resistance, ${ }^{\circ} \mathbf{C}$ \\
\cline { 3 - 5 } & $80-100$ & $0.4-0.8$ & $0.5-1.0$ & 280 & $800-900$ \\
АСПК & $50-60$ & $0.4-0.5$ & $0.5-1.0$ & 260 & $1100-1200$ \\
АКТМ & $32-38$ & $2.2-3.1$ & $0.7-0.9$ & 70 & $1100-1200$ \\
Borazon & $30-38$ & $2.0-4.0$ & $1.2-1.5$ & 100 & $1000-1100$
\end{tabular}

Comparing the mechanical properties in the Table 2 for the possibility of using Hexanit as the core material for diamond smoothing, the following conclusions can be made. Assuming the microhardness of the materials to be processed, for example, for copper - $0.8 \mathrm{GPa}$, for steel $10 \mathrm{GPa}$, it is possible to assume that microhardness with a minimum value of $30 \mathrm{GPa}$ is sufficient. Heat resistance has the best value. Thermal conductivity deteriorates, but it has better indications for Hexanit than for borazon. But there is thermal conductivity at a value of $100 \mathrm{~W} /(\mathrm{m} \mathrm{K})$, significantly higher than the thermal conductivity of a steel mandrel $-30 \mathrm{~W} /(\mathrm{m} \mathrm{K})$, in which the core is fixed. In addition, in comparison with borazon, Hexanit, with a slight decrease in hardness, has a greater depravity and viscosity, which allows it to work better in conditions of shock loads.

As is known from the Table $\mathbf{2}$ Hexanit microhardness is such that its processing is possible on diamond wheels. Therefore, it is not difficult to grind a replaceable tip with a core from "Hexanit-R" to the workpiece stage for shaping the working surface. In the tips, in most cases, a core with "Hexanit-R" is used in the form of a cylinder with a diameter of $6 \mathrm{~mm}$ and a height of $8 \mathrm{~mm}$, then sharpening takes place at the required cutting angles. Therefore spoiled replaceable tips made of SHM, can be used as blanks for smoother, which require either re-regrind or disposal (Fig. 4).

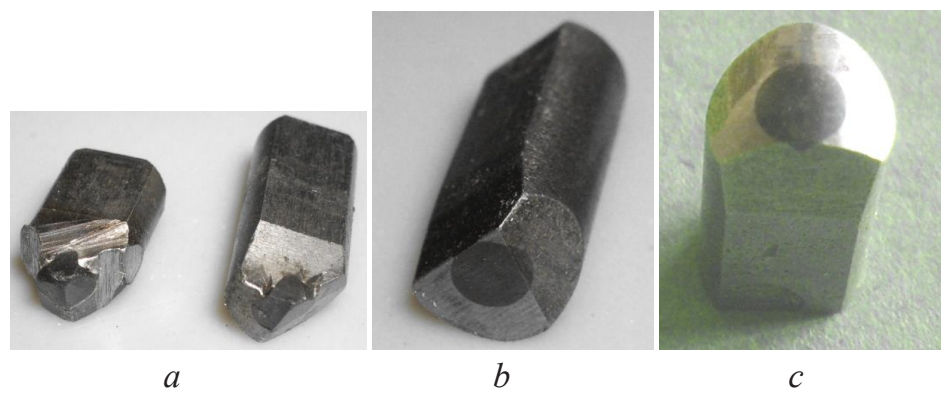

Fig. 4. Variable tips made of "Hexanit-R" SHM: $a$ - damaged, which require either regrinding or disposal; $b$ - prepared for reuse as diamond knurling; $c$ - formed for use as a diamond knurler

Studies were performed on samples of steel grade St10. Let's assign a radius of curvature for the knurler $5 \mathrm{~mm}$ in the longitudinal direction as for the material to be processed - non-hardened steel. To facilitate sharpening the working part of the shaping in the vertical direction was not carried out. This is due to the following. The working part of the knurler in the vertical plane is in contact with the convex surface of the workpiece, providing the necessary limited contact spot. The specified contact spot is sufficient for diamond knurling. The working part of the diamond wheel formed after knurling is shown in Fig. $\mathbf{4}, \boldsymbol{c}$.

To fix the knurler on the lathe, a mandrel was made, which allows a spring-loaded clamp of the knurler to the workpiece. Sketch drawing and appearance of the mandrel for diamond knurling is shown in Fig. 5.

It is proposed to compensate for the lack of vertical shaping of the working part of the knurler by accurately adjusting the setting of the knurler relative to the axis of the workpiece being processed (Fig. 6). In the tool holders of the lathe, the mandrel shank is clamped so that the center of the core of the knurling tip falls exactly on the axis of the workpiece being machined. The specified adjustment is provided by pre-installation in a three-jaw chuck instead of the machining part of the template, which accurately determines the rotation axis of the workpiece. The indicated procedure can also be controlled using the tip of the rear rotating center. 


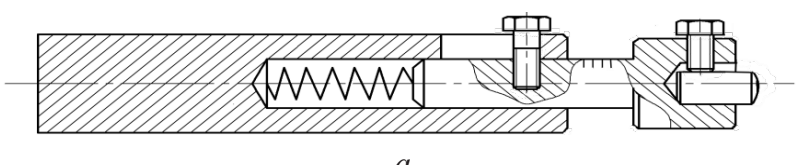

a

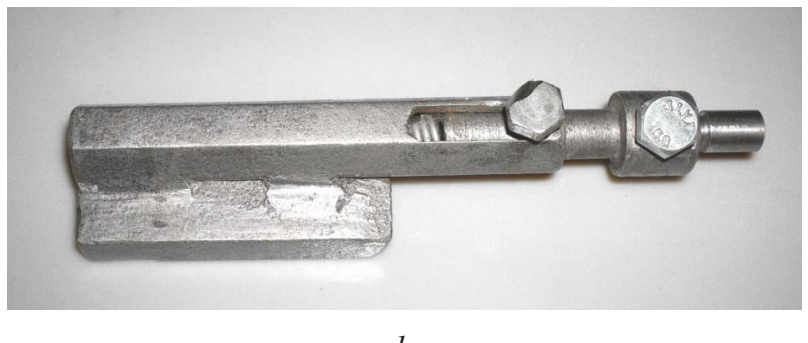

$b$

Fig. 5. The design of the mandrel for diamond knurling: $a$ - outline sketch; $b$-appearance

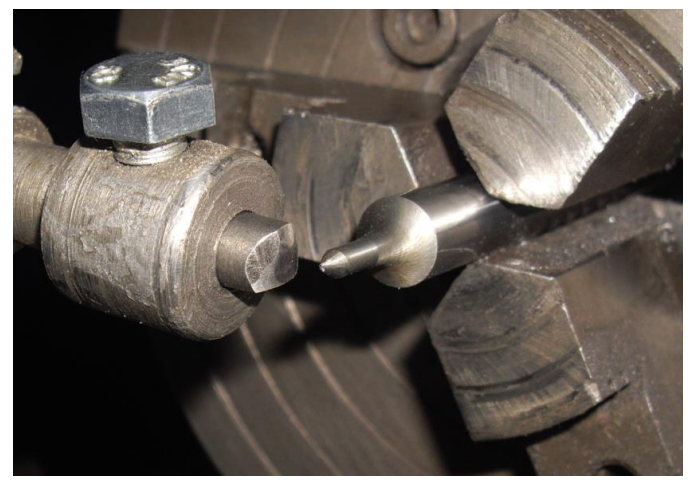

Fig. 6. Pre-installation of the mandrel for diamond knurling

Calibration of the clamping force was carried out as follows. The mandrel for diamond knurling was installed vertically and loaded with a load from above, the weight of which was known. The distance between the movable and fixed parts was controlled by the number of divisions that are applied to the moving parts of the snap (Fig. 5, a). Compiled calibration table determined the pressure force.

\section{Research results and discussion}

The study was carried out by knurling the shaft necks on the workpieces made of St10 material after its semi-finished turning. The control of the achieved roughness was carried out using roughness samples. Fig. 7 shows the process of diamond knurling of shaft necks made of St10 material by a knurled bed made of "Hexanit-R" material.

Both "hard" and "flexible" contact of the knurler with the machining surface was considered. The indicated modes can be easily organized by changing the spring stiffness in the mandrel for diamond knurling - "flexible" contact, or replacing it with a steel core - "hard" contact.

The interest in using "hard" knurling, but with the use of the available equipment, could not get any positive results. As the knurler was approaching, a process of tearing out metal particles from the workpiece took place. Obviously, from the radial runout of the workpiece and the insufficient rigidity of the machine-device-tool-part (MDTP) technological system, it is impossible to provide a normalized fixed clamping force.

"Flexible" contact is more favorable, because it allows to compensate for the shortcomings of the "hard" - radial runout of the workpiece and insufficient rigidity of the MDTP system. In addition, it allows knurling of the workpiece surfaces during its re-installation, when the installation error inevitably appears. Sometimes, if necessary, re-clamping the workpiece on the machine, knurling processing allows to reduce the diametrical size of the workpiece by a small size, where changing the diametrical size by removing chips is impossible.

Research of the knurling process was carried out with the following parameters: knurler radius $5 \mathrm{~mm}$, clamping force $200 \mathrm{~N}$; feed $0.05 \mathrm{~mm} / \mathrm{rev}$; roll speed $50 \mathrm{~m} / \mathrm{min}(630 \mathrm{rpm}$ with a 
workpiece diameter of $25 \mathrm{~mm}$ ). The parameters of knurling should be taken as recommended for diamond smoothing. The process of diamond knurling is shown in Fig. 7, $\boldsymbol{a}$. The processing results are as follows. During diamond knurling, the resulting high-quality cylindrical surface is obtained. The roughness of the shaft surface after the semi-turning is Ra 3.2. After knurling, a roughness of Ra 0.8 becomes achievable; roughness improvement took place at 3 gradations. Knurling was carried out with lubrication with I-20A mineral industrial oil.

The specified surface is obtained by quadruple passage of the processed surface by the knurler. It is found that an increase in the number of passes does not lead to a significant improvement in surface roughness. Increasing the processing productivity by increasing the knurling modes such as speed, or feed, or pressing force led to a noticeable heating of the knurler, which leads to its rapid destruction.

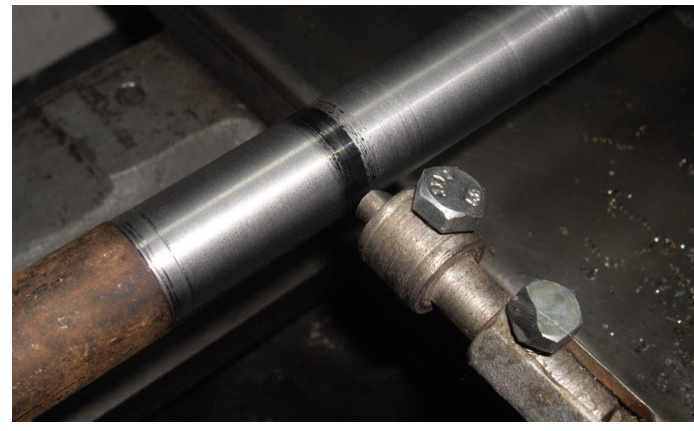

$a$

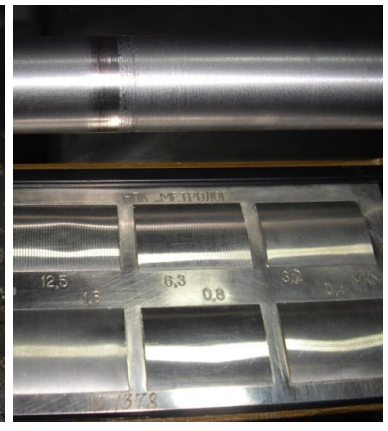

$b$

Fig. 7. Diamond knurling of shaft necks made of St10 material by knurler made of "Hexanit-R" material: $a$ - knurling process; $b$-determination of the obtained roughness

The tip operating time after diamond knurling has a life of up to 40 hours, there are no consequences or wear, or damage to the working surface, shown in Fig. 8.

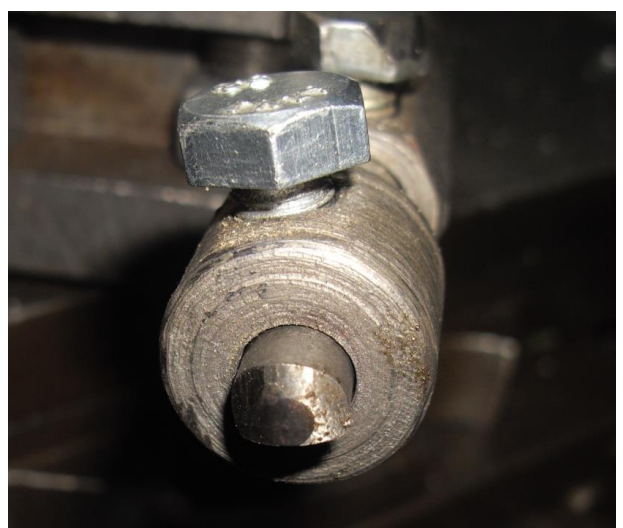

Fig. 8. The view of the working surface of the knurler made of "Hexanit-R" after 40 hours of operation

\section{Conclusions}

Based on the research results, the following can be established:

1. The possibility of using "Hexanit-R" SHM as a material for the working part of the diamond-based knurler as a material, which is widely represented in turning tools at every workplace of a turner in a single or small-scale production, has been confirmed. The knurler is installed in a spring-loaded mandrel, the manufacture of which does not present any difficulties. The main condition for which is the absence of knurler backlashes relative to the tool holder, where the mandrel is installed.

2. The type of regrinding of tips from turning tools with "Hexanit-R" SHM with a radius of $5 \mathrm{~mm}$ only in the vertical plane has confirmed its operability for use as a diamond knurler for knurling of workpieces made of St10 material provided that the knurling core is accurately located relative to the axis of rotation of the workpiece. 
3. The processing modes for the diamond knurling operation for tips from "Hexanit-R" SHM workpieces from St10 material are as follows: clamping force $200 \mathrm{~N}$; feed $0.05 \mathrm{~mm} / \mathrm{rev}$; roll speed $50 \mathrm{~m} / \mathrm{min}$. After 40 hours of life tests, no changes or signs of wear are observed on the working surface of the knurler at all. As a result of diamond knurling of the workpiece surface, the roughness with $\mathrm{Ra} 3.2$ is improved to $\mathrm{Ra} 0.8$. At the same time, a slight decrease in the diametric size is observed.

\section{References}

[1] Vasilyev, A., Popov, S., Vasilyev, E., Pavelieva, A. (2017). Improving the method of rotational broaching in the production of profile openings on the lathes of turning group. Eastern-European Journal of Enterprise Technologies, 1 (1 (85)), 4-9. doi: http://doi.org/10.15587/1729-4061.2017.92256

[2] Vasilyev, Ye. A., Popov, S. V., Vasilyev, A. V. (2016). Improving the efficiency of deep drilling with spiral drills in the processing of parts made of steel material 40. Bulletin of the National Technical University «Kharkiv Polytechnic Institute». Series: Mechanical-technological systems and complexes, 49 (1221), 75-79.

[3] Aliev, I. S., Matviychuk, V. A. (2008). Investigation of the influence of surface plastic deformation on the state of the surface layer and service characteristics of products. Newsletter of Kyiv Polytechnic. In-t machine-blowing, 54, 13-20.

[4] Stepanova, T. Yu. (2009). Technology of surface hardening of machine parts. Ivanovo: Ivan. state chemical technol. Univ., 64.

[5] Kabatov, A. A. (2013). Analysis of finishing methods of surface plastic deformation processing. Open information and computer integrated technologies, 58, 49-54.

[6] Dyl, T. (2011). The burnishing strengthen shafts neck of centrifugal pumps. Journal of KONES Powertrain and Transport, 8 (2), 123-128.

[7] Borkar, A. P., Kamble, P. S., Seemikeri, C. Y. (2014). Surface Integrity Enhancement of Inconel 718 by using Roller Burnishing process. Journal of Current Engineering and Technology, 4 (4), 2595-2598.

[8] Kundrak, J., Felho, C. (2016). 3D parameters of surface face milled by special tools. Manufacturing Technology, 16 (3), 532-538.

[9] Gomez-Gras, G., Travieso-Rodriguez, J. A., Jerez-Mesa, R. (2015). Experimental Characterization of the Influence of Lateral Pass Width on Results of a Ball Burnishing Operation. Procedia Engineering, 132, 686-692. doi: http://doi.org/10.1016/j.proeng. 2015.12.548

[10] Loh, N. H., Tam, S. C. (1988). Effects of ball burnishing parameters on surface finish - A literature survey and discussion. Precision Engineering, 10 (4), 215-220. doi: http://doi.org/10.1016/0141-6359(88)90056-6

[11] Posdzich, M., Stöckmann, R., Morczinek, F., Putz, M. (2018). Investigation of a plain ball burnishing process on differently machined Aluminium EN AW 2007 surfaces. MATEC Web of Conferences, 190, 11005. doi: http://doi.org/10.1051/matecconf/ 201819011005

[12] Smoothers made of synthetic diamonds $\mathrm{R}_{\text {vert. }}=1 \mathrm{~mm}(\Phi 10 \mathrm{x} 12) 0.8$ carats 624 UAH. Available at: https://prom.ua/p839916405vyglazhivateli-sinteticheskih-almazov.html Last accessed: 27.12 .2019

[13] Vyglazhivatel almaznii ST-5 s okhlazhdeniem. Available at: https:/tiu.ru/p214967902-vyglazhivatel-almaznyj-ohlazhdeniem. html Last accessed: 27.12.2019

[14] Cutter hexanite-R (D8xH6.5xL16) angle 45/15 boring (601102) 300 UAH. Available at: https://prom.ua/p671602147-rezetsgeksanit-rd8hh65hl16.html Last accessed: 27.12.2019 